\title{
Application of integrated geophysical methods for site suitability of Research Infrastructures (RIs) in China
}

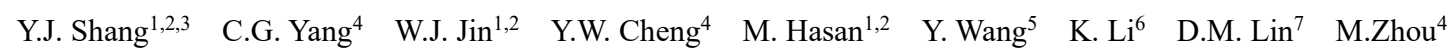

1. Institute of Geology and Geophysics, Chinese Academy of Sciences, Beijing 100029, P.R.China;

2. Innovation Academy for Earth Science, Chinese Academy of Sciences, Beijing 100029, P.R.China;

3. University of Chinese Academy of Sciences, Beijing 100049, P.R.China;

4. Institute of High Energy Physics, Chinese Academy of Sciences, Beijing 100049, P.R.China;

5. Institute of Modern Physics, Chinese Academy of Sciences, Lanzhou 730000, P.R.China;

6. General Institute of Water Resources and Hydropower Planning and Design, Beijing100120, P.R.China;

7. Research Institute of Highway Science, Ministry of Transportation, Beijing 100088, P.R.China

Abstract Research Infrastructures (RIs) are essential to achieve excellence in innovative scientific research. However, because of limited land availability and specific geological requirements, evaluating the viability of a site for a new RI can be a challenging task. Stringent safety construction requirements include developing site-specific architectural and geoengineering solutions, minimizing construction disturbances, and reinforcing rock and soil in a timely fashion. For successful development of the RIs in China, such as the Daya Bay Neutrino Laboratory (DBNL), and the China Spallation Neutron Source (CSNS), an integrated approach of joint geophysical methods including the electrical resistivity tomography (ERT), controlled-source audio-frequency magneto telluric (CSAMT)), gravity and seismic refraction methods, and geological mapping and surveys were carried out. Geophysical parameters, such as electrical resistivity, density, and seismic velocity show inverse proportion to the degree of rock fracturing or weathering. The results show that the low values of geophysical parameters suggest the weathered/fractured rock, while high values reveal the fresh bedrock. The Engineering Geological Suitability Index (EGSI) value can represent the individual EGSI values at a constant and summed over varying depths. EGSI methodology is an improvement on the existing siting process, and has been applied this to CSNS. Our integrated approach provides clearer insight of the subsurface for site suitability of RIs in 
challenging engineering geological conditions, and removes any ambiguity caused by a single geophysical parameter. The obtained geological knowledge of the area not only provides engineers with much-needed information about the construction conditions of a potential site, but also gives scientists the opportunity to explore the local geology. In this study, we demonstrate our innovative approach for siting RIs, as demonstrated by the synthetic evaluation of the site location and utilization for two established RIs (DBNL and CSNS).

Keywords: Research Infrastructures (RIs); Engineering Geological conditions; Integrated geophysical methods; Daya Bay Neutrino Laboratory (DBNL); China Spallation Neutron Source (CSNS).

\section{Introduction}

Research Infrastructures (RIs) play an important role in exploring the unknown world and represent an incomparable research asset. While some smaller RIs are built by individual institutions, some instruments or facilities are large enough that they must be constructed and maintained by one or more national organizations (Horvat, 2011).These large-scale RIs (for distribution see Fig.1a) provide many countries and scientists with the opportunity to explore both specialized and interdisciplinary topics (Pero, 2011; Florio and Sirtori, 2016; Qiao et al., 2016). During the planning stages for RIs, such as Homestake (Kevin et al.,2007) and the Jinping Underground Laboratory (CJPL)(Feng et al., 2016), one of the main issues engineers faced was selecting a location site with the appropriate geological characteristics. Despite the fact that a lack of local geological knowledge can be problematic for RI developers, few studies have analyzed the siting of RIs from a geoengineering sustainability perspective (Li et al., 2017). 


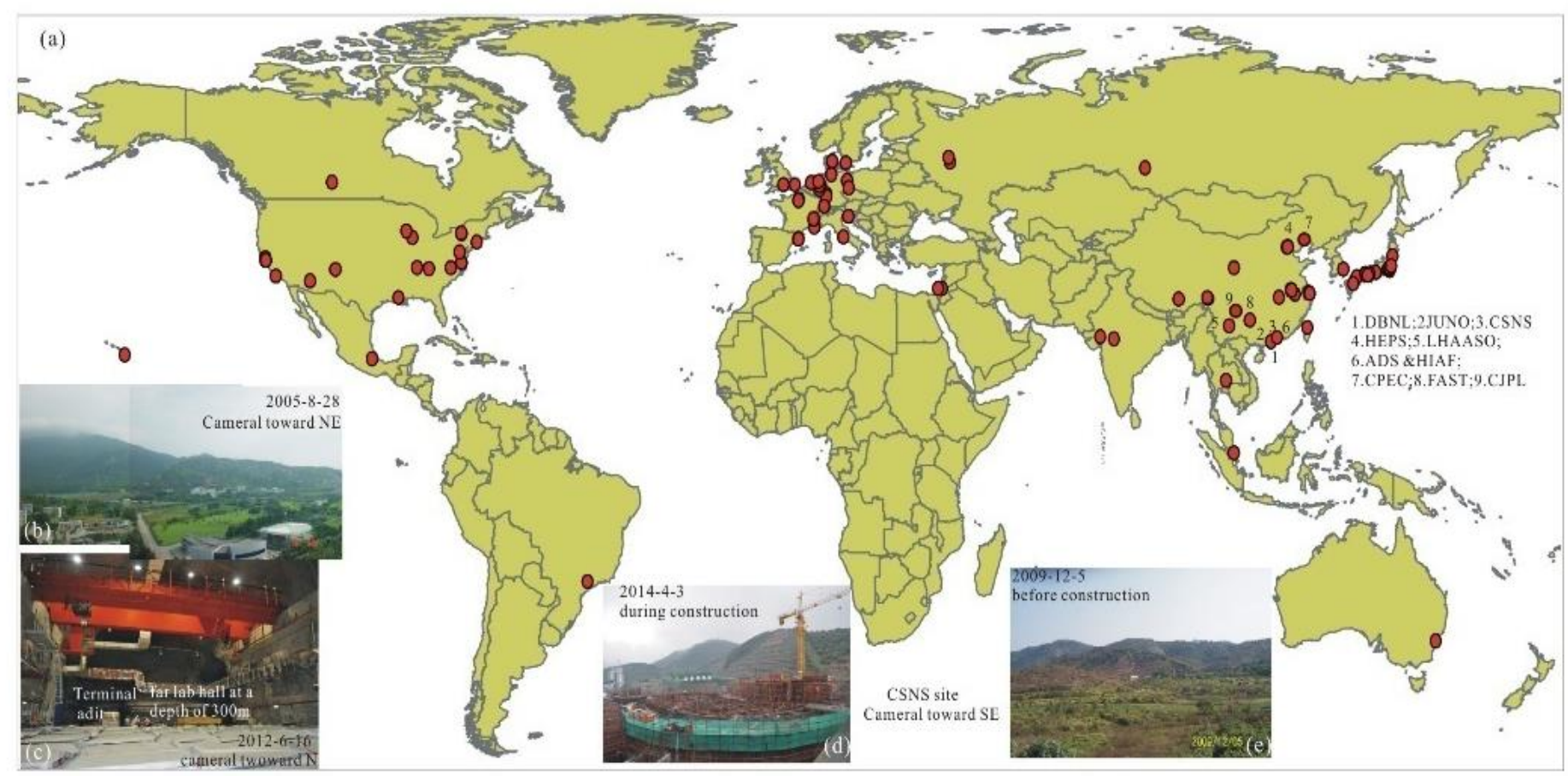

Figure 1. Distribution of the RIs worldwide and images of the DBNL and CSNS sites. (a)Distribution of RIs worldwide (location data from MSTI, 2009), including the nine Chinese sites discussed in this paper. (b) Geography of the DBNL site. (c)The far hall of the DBNL site during construction. (d)The CSNS site during construction. (e) Geography of the CSNS site.

Given the complex and variable geological conditions observed throughout China, an RI site assessment is not complete without subsurface geological data. The local subsurface geological information is vital since it provides the site selection, which can, in turn, affect the ability of those using the RI facilities to achieve their scientific objectives. In 1984 the results of the survey conducted at the Babaoshan active fault zone $(\mathrm{Gu}, 2015)$ played a role in determining the site of the Beijing Electron Positron Collider (BEPC), which opened in October of 1988 (Zhang, 2004). The China initiative Accelerator Driven System (CiADS) core device location and the High Elevation Cosmic Ray Observatory (LHAASO) site (see 5-2 in Table 1) were both moved to avoid fault zones and the corresponding complex hydrological conditions.

Table1.The nine large scale RIs in various stages of completion in China.

\begin{tabular}{|c|c|c|c|c|c|c|c|c|}
\hline No & Name & $\begin{array}{c}\text { Geological } \\
\text { characteristics }\end{array}$ & Location & $\begin{array}{c}\text { Site } \\
\text { selection } \\
\text { periods }\end{array}$ & Investigation result & $\begin{array}{l}\text { Evaluation } \\
\text { result }\end{array}$ & $\begin{array}{l}\text { Construction period } \\
\text { and operation result }\end{array}$ & Ref. \\
\hline 1 & $\begin{array}{l}\text { Daya Bay Neutrino } \\
\text { Laboratory (DBNL) }\end{array}$ & $\begin{array}{l}\text { Granite tunnel } \\
\text { and hall }\end{array}$ & $\begin{array}{r}\text { Daya Bay, } \\
\text { Shenzhen }\end{array}$ & $\begin{array}{l}2005- \\
2006\end{array}$ & $\begin{array}{l}\text { South limb of } \\
\text { Paiyashan syncline, } \\
\text { granite contact with } \\
\text { Devonian sandstones. } 4 \\
\text { weathering troughs, } 3\end{array}$ & $\begin{array}{l}\text { Site } \\
\text { suitability }\end{array}$ & $\begin{array}{l}\text { 2007-2011, 2013; } \\
\text { innovative scientific } \\
\text { outcomes }\end{array}$ & $\begin{array}{l}\text { Wang et al., } \\
2016\end{array}$ \\
\hline
\end{tabular}




\begin{tabular}{|c|c|c|c|c|c|c|c|c|}
\hline & & & & & faults & & & \\
\hline 2 & $\begin{array}{l}\text { Jiangmen } \\
\text { Underground } \\
\text { Neutrino Observatory } \\
\text { (JUNO) }\end{array}$ & $\begin{array}{l}\text { Sandstone } \\
\text { inclined shaft, } \\
\text { granite shaft } \\
\text { and hall }\end{array}$ & $\begin{array}{l}\text { Kaiping, } \\
\text { Jiangmen }\end{array}$ & $\begin{array}{l}2011- \\
2013\end{array}$ & $\begin{array}{l}\text { Granite contact with } \\
\text { sandstone } \\
\text { complex fold }\end{array}$ & $\begin{array}{l}\text { Site } \\
\text { suitability }\end{array}$ & $\begin{array}{l}\text { 2014-2020, under } \\
\text { construction }\end{array}$ & $\begin{array}{l}\text { Shang et al., } \\
2014\end{array}$ \\
\hline 3 & $\begin{array}{lr}\text { China } & \text { Spallation } \\
\text { Neutron } & \text { Source } \\
\text { (CSNS) } & \end{array}$ & $\begin{array}{l}\text { Buried tunnel } \\
\text { and } \\
\text { basement in } \\
\text { compound } \\
\text { gneiss and } \\
\text { granite }\end{array}$ & $\begin{array}{l}\text { Dalang, } \\
\text { Dong'gua } \\
\mathrm{n}\end{array}$ & $\begin{array}{l}2006- \\
2009\end{array}$ & $\begin{array}{l}\text { Weathering profile with } \\
50 \mathrm{~m} \text { thickness troughs, } \\
\text { and } 4 \text { faults }\end{array}$ & $\begin{array}{l}\text { Site } \\
\text { suitability }\end{array}$ & $\begin{array}{l}2010-2016, \quad \text { in } \\
\text { operation }\end{array}$ & $\begin{array}{l}\text { Shang et al., } \\
2014 \text {; Li et al., } \\
2017\end{array}$ \\
\hline 4 & $\begin{array}{l}\text { High Energy Photon } \\
\text { Source Test Facility } \\
\text { (HEPS) }\end{array}$ & $\begin{array}{l}\text { Buried tunnel } \\
\text { and basement } \\
\text { in sandy } \\
\text { gravel layer }\end{array}$ & $\begin{array}{l}\text { Huairou, } \\
\text { Beijing }\end{array}$ & $\begin{array}{l}2011- \\
2017\end{array}$ & $\begin{array}{l}300 \mathrm{~m} \text { sandy gravels } \\
\text { over granite and } \\
\text { fractured pyroclastic } \\
\text { rocks in west of } \\
\text { Gaoliying active fault }\end{array}$ & $\begin{array}{l}\text { Site } \\
\text { foundation } \\
\text { (medium } \\
\text { complex) }\end{array}$ & $\begin{array}{l}\text { Abandoned due to } \\
\text { granite margin, } \\
\text { afterwards, a site was } \\
\text { selected } 5 \mathrm{~km} \text { north } \\
\text { ward with larger area } \\
\text { of granite in 2018, } \\
\text { currently under } \\
\text { construction }\end{array}$ & $\begin{array}{l}\text { Shang et al., } \\
2014 \text {; Shang } \\
\text { et al., 2018b }\end{array}$ \\
\hline $\begin{array}{c}5- \\
1\end{array}$ & $\begin{array}{l}\text { High Altitude Cosmic } \\
\text { Ray Observatory } \\
\text { (LHAASO) }\end{array}$ & $\begin{array}{l}\text { Mudstone, } \\
\text { limestone } \\
\text { basement and } \\
\text { slope }\end{array}$ & $\begin{array}{l}\text { Zhongdian } \\
\text {, Yun'nan }\end{array}$ & 2013 & $\begin{array}{l}\text { Over } 118 \text { sinkholes, } 12 \\
\text { water-accumulating } \\
\text { depressions, landslides } \\
\text { and sand slopes, } 4 \\
\text { uphill routes }\end{array}$ & unsuitable & $\begin{array}{l}\text { Abandoned due to } \\
\text { karst development }\end{array}$ & $\begin{array}{l}\text { Shang et al., } \\
2018 \mathrm{a}\end{array}$ \\
\hline $\begin{array}{l}5- \\
2\end{array}$ & $\begin{array}{l}\text { High Altitude Cosmic } \\
\text { Ray Observatory } \\
\text { (LHAASO) }\end{array}$ & $\begin{array}{l}\text { Granite } \\
\text { basement and } \\
\text { slope }\end{array}$ & $\begin{array}{l}\text { Daocheng, } \\
\text { Sichuan }\end{array}$ & $\begin{array}{l}2013- \\
2014\end{array}$ & $\begin{array}{l}\text { Glacier remnants of } \\
\text { plateau ice cap, river } \\
\text { side beach }\end{array}$ & $\begin{array}{l}\text { Medium } \\
\text { suitable }\end{array}$ & $\begin{array}{l}\text { 2016, currently under } \\
\text { construction }\end{array}$ & $\begin{array}{l}\text { Shang et al., } \\
2014\end{array}$ \\
\hline $\begin{array}{c}6- \\
1\end{array}$ & HIAF and ADS & $\begin{array}{c}\text { Sandstone } \\
\text { basement } \\
\text { and slope }\end{array}$ & $\begin{array}{l}\text { Dongshen } \\
\text { g, Inner } \\
\text { Mongolia }\end{array}$ & 2012 & $\begin{array}{l}\text { Strong permeability of } \\
\text { rock mass, storage of } \\
\text { surface flood }\end{array}$ & unsuitable & $\begin{array}{l}\text { To consider other } \\
\text { places including } \\
\text { Shandong, Jiangsu } \\
\text { and Guangdong }\end{array}$ & $\begin{array}{l}\text { Shang et al., } \\
2014\end{array}$ \\
\hline $\begin{array}{l}6- \\
2\end{array}$ & HIAF and ADS & $\begin{array}{l}\text { Dacite, } \\
\text { Pyroclastic } \\
\text { rocks } \\
\text { basement } \\
\text { and slope }\end{array}$ & $\begin{array}{l}\text { Huizhou, } \\
\text { Guangdon } \\
\text { g }\end{array}$ & 2014 & $\begin{array}{l}\text { Strong permeability of } \\
\text { rock mass and } 40 \mathrm{~m} \\
\text { weathering profile }\end{array}$ & $\begin{array}{l}\text { Medium } \\
\text { suitable }\end{array}$ & Under construction & $\begin{array}{l}\text { Hasan et al., } \\
2018\end{array}$ \\
\hline 7 & $\begin{array}{lr}\text { Circular } & \text { Electron- } \\
\text { Positron } & \text { Collider } \\
(\mathrm{CPEC}) & \end{array}$ & Granite tunnel & $\begin{array}{l}\text { Zhangjiak } \\
\text { ou, } \\
\text { Chengde, } \\
\text { qinghuang } \\
\text { dao, } \\
\text { Guangdon } \\
\text { g }\end{array}$ & $\begin{array}{l}2013- \\
\text { present }\end{array}$ & $\begin{array}{lr}\text { Soft } & \text { Foundation, } \\
\text { Uneven Settlement and } \\
\text { Moving } \\
\text { Treatment }\end{array}$ & $\begin{array}{l}\text { Funing } \\
\text { granite in } \\
\text { Qinhuangdao, } \\
\text { Huizhou } \\
\text { granite }\end{array}$ & Site selection & $\begin{array}{l}\text { Shang et al., } \\
2014\end{array}$ \\
\hline 8 & $\begin{array}{l}\text { Five-hundred meters } \\
\text { Aperture Spherical } \\
\text { Telescope (FAST) }\end{array}$ & $\begin{array}{l}\text { Limestone } \\
\text { basement }\end{array}$ & $\begin{array}{l}\text { Pingtang, } \\
\text { Guizhou }\end{array}$ & $\begin{array}{l}2006- \\
2007\end{array}$ & $\begin{array}{l}\text { Karst depression with a } \\
\text { diameter of } 500 \mathrm{~m}\end{array}$ & $\begin{array}{l}\text { Basement } \\
\text { stability and } \\
\text { runoff } \\
\text { discharge } \\
\end{array}$ & $\begin{array}{l}2008-2013 \\
\text { operation }\end{array}$ & $\begin{array}{l}\text { Song et al., } \\
2007\end{array}$ \\
\hline 9 & $\begin{array}{l}\text { Jinping underground } \\
\text { laboratory(CJPL) }\end{array}$ & Marble tunnel & $\begin{array}{l}\text { Jinping, } \\
\text { Sichuan }\end{array}$ & 2008 & $\begin{array}{l}\text { High geostress and rock } \\
\text { burst }\end{array}$ & $\begin{array}{l}2400 \mathrm{~m} \text { deep } \\
\text { incomplete } \\
\text { marble }\end{array}$ & $\begin{array}{c}2009-2010, \\
\text { operation }\end{array}$ & $\begin{array}{l}\text { Feng et al., } \\
2016\end{array}$ \\
\hline
\end{tabular}

Because China is cognizant of social changes and developments, the country is investing heavily in strategic long-term scientific programs (Marcelli, 2014).During the XI Five-Year period (2006-2010), China built twelve major science and technology RIs. China has 32RIs that are either being constructed or are fully operational (SCC, 2013).The XIII Five-Year Plan for the National Major Science and Technology Infrastructure Construction(2016-2020) proposes that by 2020,55major science and technology infrastructures will be either be up and running or in the process of being built (NDRC, 2017).

Land resources have become increasingly scarce because of China's rapid social and economic development, behaving with a largest infrastructure system forming the backbone of the society from current stock and forecast future needs to 2040 (Scott et al., 2019). As such, there are very few 
ideal and full satisfied sites with simple geological conditions that can meet the RI engineering requirements. During site selection of nine large-scale RIs in areas with relatively complex geological conditions, planners had to decide how to most efficiently gather the local geological data that would determine whether the site was an appropriate RI location (Table1). Placing the efforts to change the perceived lack of science in the context of China's turbulent modern history is the key to understanding how the nation arrived at its current superpower state (Wu, 2019), the approaches adopted are different from the definition of qualitative indicators serving as basis to map the ecosystem service (Lisa et al., 2016).The quality of digital elevation models (DEMs) and spatial resolution are important issues in geomorphic studies. But the highest accuracy was attained from there sampled $30 \mathrm{~m}$ LiDAR DEM derivatives, indicating a fine-resolution topographic data does not necessarily achieve the best performance (Chang et al., 2019).The introducing variable weightanalytical hierarchy process-comprehensive index model for evaluation of the suitability of agricultural land and construction land can provide some geological basis for the future regional land utilization zoning (Gao et al., 2019).The simple random variable model might outperform the complex random field model in predicting the geotechnical system, while considering the uncertainty in the model parameters (Juang et al., 2018).

To visualize geological structures and identify harmful geological bodies in advance, engineers often develop geological plane and section drawings in order to properly site the RIs. For capturing some of the key risk factors for the purposes of a comparison of repository site, a brief commentary highlighting contrasts between onshore and offshore locations in relation to multiple factors was a primary issue (Stewart, 2002).With high quality geological site data, a crystalline rock mass for hydraulic stimulation experiments can be describing (Hannes et al., 2018), RIs can be designed so that the location of each facility and instrument is optimized.

\section{RIs Requirements and approaches}

Site selection for large RIs requires geotechnical analyses that ensure the long-term stability of the area beneath and around the RI site. Prior to this study, no systematic RI site selection methodology has been reported either in China or elsewhere. This new field of inquiry will require comprehensive case studies at multiple locations before the methodology is robust enough for wider application worldwide. 
Our RI site selection investigation was applied at six Chinese RIs. They included the Daya Bay Neutrino Laboratory (DBNL), the China Spallation Neutron Source (CSNS), the High Elevation Cosmic Ray Observatory (LHAASO), the High Energy Photon Source Test Facility (HEPS), the High Intensity heavy-ion Accelerator Facility (HIAF) and the China initiative Accelerator Driven System (CiADS). These geoengineering studies revealed that the geological structure and the structural plane of the rock mass can disturb the mechanical balance of the geological body, which may result in weakening of the geological body and the stability of the engineered structures at the sites.

From the approach called as jade carving in China (i.e., maximum utilization of a site with a few of poor geological conditions) to deal with unfavorable constraints, we incorporated geological surveys, geophysical exploration, and information system technologies into our analysis, and made suggestions for the siting, construction, and running of six projects (Table 1). Furthermore, this geological background information may affect the observational data collected in the course of RI operating activities. These geotechnical analyses were undertaken for siting purposes prior to the construction of the main facilities. Table 2 shows the time line for RI sites election and engineering.

Table2. Timeline for sites election and engineering of RIs.

\begin{tabular}{cllll}
\hline Phase & \multicolumn{1}{c}{ Name } & Evaluation & \multicolumn{1}{c}{ Objectives } & \multicolumn{1}{c}{ Main problems } \\
\hline 1 & Site selection & Suitability & Geological model & Discontinuity \\
2 & Plan and design & Feasibility & Parameters & Discrete layers \\
3 & Construction & Disturbance & Materials & Unfavorable geological body \\
4 & Operation & Reliability & Rebalance & Complex site evolution \\
\hline
\end{tabular}

\section{Geological conditions}

The geography of the six potential sites (CSNS, DBNL, JUNO, HIAF and ADS, HEPS, and LHAASO) for large-scale RIs can be categorized as consisting of plains, hills, mountains, or plateaus, with elevations ranging from tens of meters to more than 4,000 meters. The geology of these sites is typically composed of sandy gravel soil, volcanic rocks, granite, gneiss, and marble. Within these host rock we identified problematic geological bodies, such as saprolites (i.e. residual soils and completely decomposed granites), fractured rocks, and mud layers. Additionally, intermediate acidic dykes are susceptible to fracturing under weathering and rapid changes in the 
amount and orientation of stress.

Granite, gneiss, and sandstone are the lithology most commonly found at the two RI sites (DBNL and CSNS) we discuss in this study. In order to better understand these host rocks, we conducted microscopic, textural (IGGCAS 2006; 2007), physical, mechanical, and hydrogeological analyses on samples from the RIs sites. We also collected boreholes that sampled granites (DBNL and CSNS) and gneisses (CSNS) to refine our understanding of the stratigraphy and structure of the local geology. Long borehole cores, up to $1.7 \mathrm{~m}$ in length, ensured that we were reliably capturing the essential subsurface characteristics of each RI site(Fig. 2).
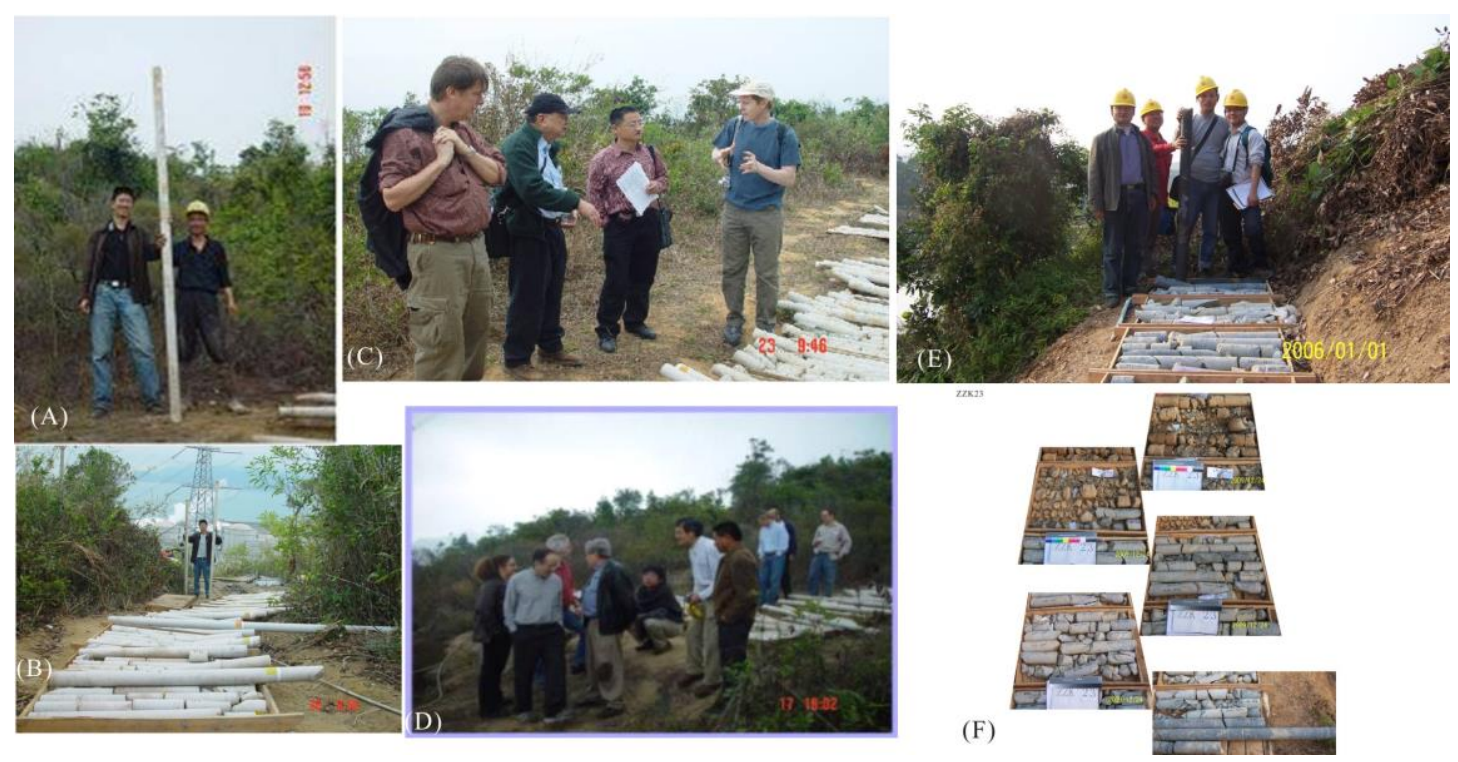

Fig. 2 Figure 2. Drilled cores in the RIs sites (DBNL and CSNS).

(a) Borehole core with a length greater than $2 \mathrm{~m}$ in one drilling event at ZK2 at the DBNL site. (b)

Borehole cores with lengths greater than $2 \mathrm{~m}$ in one drilling event at ZK3 at the DBNL site. (c)

Discussion between experts from an American national lab at ZK4 at the DBNL site. (d)

Discussion between scholars with expertise in high energy physics at the DBNL site. (e)

Borehole cores with lengths of about $1.7 \mathrm{~m}$ in one drilling event at ZZK23 at the CSNS site. (f)

Drilled cores at ZZK23 used to locate the ring accelerator at the CSNS site.

(b)

Previous examples of encountering underlying adverse geological bodies during RI development include karst caves (resulting in LHAASO moving from the Shikashan in Yun'nan Province to Daocheng in Sichuan Province (Shang et al., 2018a); see 5-1 and 5-2 in Table 1, respectively), large uneven subsidence(resulting in HEPS moving northward by nearly $5 \mathrm{~km}$ to the plain area at Huairou (Shang et al., 2018b), see the 4 in Table 1), and water-rich fracture zones (Hasan et al., 
2018)(resulting in the ADS reactor moving tens of meters to the north and the LHAASO high altitude cosmic ray instrument moving hundreds of kilometers to the north of Daocheng, according to Luo(2012)). While the host rocks of the two sites (CSNS and DBNL) are mainly granite and gneiss, the subsurface geology is more complicated. The case studies of these two sites were undertaken in an effort to better understand these complex geological settings in order to facilitate the RI siting process. We used integrated geophysical techniques at the DBNL site because boreholes are unsuitable to assess the deep geologic structures in a steep slope area. Similarly, we employed the EGSI index to analyze the shallow subsurface at the CSNS site. Our interpreted model results show a strong correlation with the local geological conditions, and our recommendations were implemented in the construction of these two sites. The results of the investigations at each site are summarized below.

\section{Integrated geophysical survey for the RIs sites}

Engineering geologists deal with nature in its intrinsic variability and complexity, thus geologic uncertainties should be recognized and quantified, and considered in the engineering design and construction with helps of advanced technical tools (Juang et al., 2016). High-resolution 3D geological models are crucial for underground development projects and corresponding numerical simulations with applications (Hannes et al., 2018). In addition to using existing maps and remote sensing data to investigate the topographic and geomorphological conditions of potential RI sites.

Throughout our study, we found that electrical resistivity tomography and seismic refraction analyses are more suitable for near-surface investigations, while CSAMT and gravimetric analyses are more suitable for investigating the geology at depth. We used electrical resistivity tomography and seismic refraction techniques to define shallow subsurface formations, and the CSAMT and gravity techniques to define geologic formations at depth. The joint of gravity and seismic reflection method for the fast, large-scale characterization of hydrogeological potential have used in the Ain El Beidha plain (central Tunisia) (Azaiez,H et al. 2021).The geophysical method of gravity and magnetic as potential field is usually implemented by the $2 \mathrm{D}$ grid because these method are simply equipment, and is cheapest as well. The inversion of potential field have developed in 3D framework architecture (Sun S. et al ,2021).

\subsection{Applied geophysical methods}


Electrical resistivity is often employed to differentiate subsurface rocks from one another because the electrical resistivity is sensitive to changes in the composition, clay content, water content, porosity, and degree of fracturing in different rock samples. Furthermore, our results reveal that low resistivity values are closely associated with weathering troughs and fractured rocks, which may indicate the presence of significant groundwater resources (IGGCAS, 2011;2013a; 2013b; 2014;2015).

Gravimetric data provides information about the rock densities (in $\mathrm{g} / \mathrm{cm}^{3}$ ) and seismic refraction provides insight into the seismic velocities (in $\mathrm{m} / \mathrm{s}$ ) of the rocks sampled by the seismic waves. All these properties (electrical resistivity, density, and seismic velocity) are inversely proportional to the degree of rock fracturing or weathering. The total lengths of the seismic refraction section, the high-density resistivity section, the gravity section, and the CSAMT section are 690m, 1900m, 1820m and 720m, respectively (Fig.3).

Compared to the traditional electrical methods, the ERT provides higher resolution results at shallower depths. The ERT was conducted using a McOHM 21 (produced by the OYO Company of Japan), and the data was processed with the Gauss Newton least squares method. The seismic refraction data was acquired using a 24-channel McSeis-F170 (OYO Company of Japan) with 1024 sampling points, a sampling interval of $0.05 \mathrm{~ms}$, a geophone interval of $5 \mathrm{~m}$, and a shot point interval of $30 \mathrm{~m}$.

The high precision gravity survey was performed along the ERT profile using the CG-3 gravity meter manufactured by Scintrex (Canada) to acquire gravitational data at seven repeated observation checkpoints with a data point distance of $10 \mathrm{~m}$. The electrical resistivity tomography data and the gravimetric data were collected along the center line of all tunnels with a horizontal position error of less than $3 \mathrm{~m}($ mostly within $50 \mathrm{~cm})$ and an elevation error of less than $5 \mathrm{~cm}$.

CSAMT is a frequency domain electromagnetic (EM) method that uses a grounded dipole or loops to generate repetitive signals. CSAMT data were obtained from electric and magnetic fields oriented along and perpendicular to the traverse line, respectively. Originally, we planned to use CSAMT to capture data along the ERT profile; however, because of the sensitivity of the instrument to the high voltage power lines (present in the southern region of our study area), we only conducted the gravity survey along all of the tunnel lines. We assessed the surface and subsurface conditions using geophysical exploration techniques before borehole drilling. With a variety of geophysical 
exploration methods available, the feasibility, cost, and data quality must be considered prior to beginning these geophysical surveys. To identify problematic geological bodies that could impact the siting or engineering design of the DBNL site

\subsection{The DBNL site}

DBNL is an RI that focuses on neutrino research. The four laboratories (East Hall, Central Hall, West Hall, and Far Hall) of the DBNL are connected by tunnels (Table 3). Because these tunnels are located underground, it was vital to understand the subsurface geological structures prior to tunnel design and construction.

Table 3. Location of observation laboratory halls and boreholes at DBNL

\begin{tabular}{l|c|c|c|c|l}
\hline $\begin{array}{c}\text { Lab } \\
\text { hall }\end{array}$ & $\begin{array}{c}\text { Bottom/surface } \\
\text { elevation } \\
(\mathrm{m})\end{array}$ & $\begin{array}{c}\text { Buried } \\
\text { thickness } \\
(\mathrm{m})\end{array}$ & $\begin{array}{c}\text { Point distance- } \\
\text { DaYa/left central } \\
\text { point }(\mathrm{m})\end{array}$ & $\begin{array}{c}\text { Line distance- } \\
\text { LingAo/left central } \\
\text { point (m) }\end{array}$ & $\begin{array}{c}\text { Drilling } \\
\text { depth (m) }\end{array}$ \\
\hline West & $-23.00 / 88$ & 121 & $361.071 / \mathrm{E} 41$ & - & ZK4 \\
\hline Central & $-20.57 / 198$ & 218 & 1155.604 & 871.340 & ZK2 \\
\hline East & $-19.17 / 98$ & 117 & & $445.35 / \mathrm{W} 52$ & ZK3 \\
\hline Far & $-17.87 / 347$ & 364 & 1985.697 & 130.3 \\
\hline
\end{tabular}

The results obtained from the two seismic refraction profiles, the CSAMT profile and the gravity profile, confirm the electrical resistivity tomography observations; low resistivity values are found in the low velocity/density layer (Fig.3). The comparison between the quantitative inversion gravity profile and the electrical resistivity tomography profile shows that the central section at the location of the Kaishuiyan ditch (located at a distance of $1200 \mathrm{~m}$ on the profiles) includes a highangle fault (F6 in Fig.3); however, the ditch is revealed at depth by the electrical resistivity tomography .The faults (F1, F5, and F6 in Fig. 3), weathering troughs (2, 3, and 4 in Fig. 3), and rock contact locations constrained by ERT are consistent with those indicated by the Bouguer anomalies on the gravity profile. The maximum depth of the weathering troughs is only $120 \mathrm{~m}$ below the surface. The rock mass passing through the tunnel at depth is generally slightly weathered or 
freshrock. The 1500-meter-difference between the depth of the sedimentary rocks on the original anticline covering the granite and the granite outcrop in surface maps represents the erosional thickness, or the difference between the physical depth and the geological depth (Shang et al., 2011). The two geophysical methods (CSAMT and ERT) indicate the contact belt between the Devonian sedimentary rock and the granite intrusion with inclined angle (or steeper depth) as shown in Fig.3 ( $d$ and $f$ ). Therefore, at an elevation of $-17 \mathrm{~m}$ within the granite intrusion about $50 \mathrm{~m}$ south of the contact belt, most of the rocks are found highly resistive and dense, which was designed for sitting the far hall.

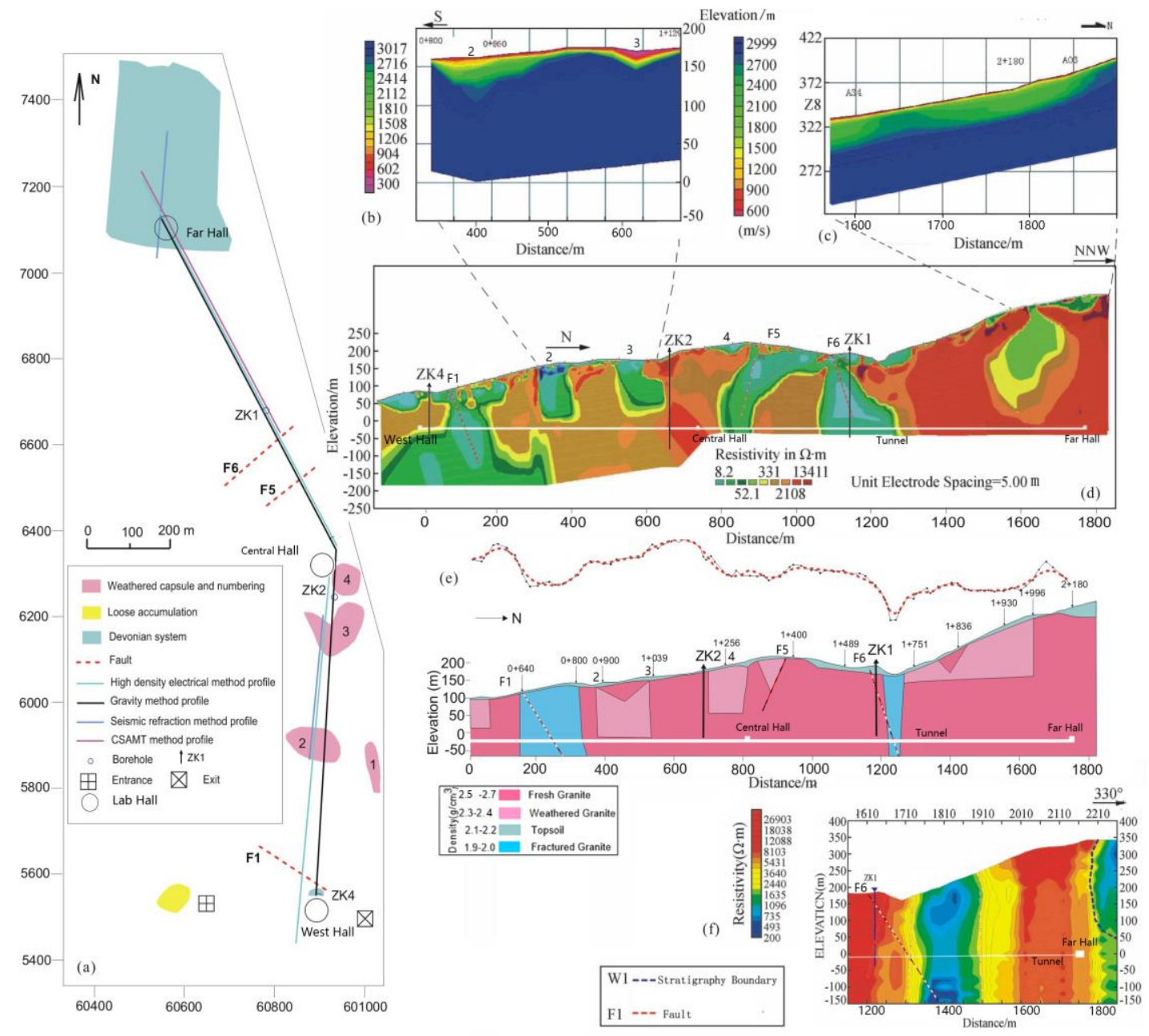

Figure3. Geophysical exploration surveys and interpreted profiles of the DBNL site.

(a)Layout of the geophysical exploration profiles along the tunneling line. (b)-(f)Interpreted profiles using different geophysical methods such as seismic refraction analyses of the (b) midhall and (c)farhall, (d)electrical resistivity tomography analyses of the west and farhalls, (e)gravimetric analyses, and (f)electromagnetic resistivity analyses(CSAMT). 
We also determined the geotechnical composition, and static and dynamic mechanical parameters of the granite and gravel soil both in-situ and in the laboratory; knowing these parameters can prove helpful when it comes to engineering designs and instrument debugging. After monitoring the long-term deformation of the problematic geological body, our proposed engineering countermeasures mitigated any possible deformation from the tunneling process to the point where the safety and stability of the project is not threatened in the future. In order to avoid the fault zone and its corresponding stress concentration zone, we recommended that the remote observation hall (far hall) of the DBNL be located at least 50m away from the contact belt, leaving a section of the tunnel terminal with a length of nearly $30 \mathrm{~m}$, where a slightly rockburst occurred during the excavation (Fig. 3f).

\section{Site suitability evaluation based on multi-factors}

We can quantify the required engineering adaptability, as characterized by RI structural matching. Ideally, we identify areas that can be built and reinforced efficiently with stable rock masses that are minimally disturbed by problematic geological bodies. Using the timely reinforcement countermeasure test (Huang, 2014) steers our analysis away from areas with a high likelihood of irreversible deformation and failure and is vital in the planning and construction of large scientific installations. By combining the data from the geological surveys, geophysical experiments, digital drilling analyses, geological structural modeling, and problematic geological body mapping, as well as engineering testing, we created a scaled 3D model of CSNS that demonstrates how the engineering structural layout is affected by changes in geological conditions (Chen, 2011; Sun et al., 2015) such as weathering and rock mass integrity.

\subsection{Site suitability evaluation methods}

In addition to calculating the $R Q D$ values for the rock masses in samples from the drilled cores, we also employed the Rock Core Index $(R C I)$ as a way to describe the integrity of the cored samples (Xu and Wang, 2006).The RCI defines the continuity of the core sample (and the rock mass it sampled):

$$
\mathrm{RCI}=1 \times \mathrm{Cr}_{1}+3 \times \mathrm{Cr}_{3}+10 \times \mathrm{Cr}_{10}+30 \times \mathrm{Cr}_{30}+50 \times \mathrm{Cr}_{50}+100 \times \mathrm{Cr}_{100}
$$

Where, $C r$ isthecoreacquisitionrate for differentdrilled core lengths(Lin, 2012). $C r_{1}, C r_{3}, C r_{10}, C r_{30}$, $\mathrm{Cr}_{50}$ and $\mathrm{Cr}_{100}$ represent the proportion of the core sections with lengths that fall into intervals of $1 \sim 3 \mathrm{~cm}, 3 \sim 10 \mathrm{~cm}, 10 \sim 30 \mathrm{~cm}, 30 \sim 50 \mathrm{~cm}, 50 \sim 100 \mathrm{~cm}$, and greater than $100 \mathrm{~cm}$, respectively. For example, if the total core length is $2.5 \mathrm{~m}$ and $100 \mathrm{~cm}$ of that core is in sections with lengths that fall 
in the $10 \sim 30 \mathrm{~cm}$ interval, and the remaining $150 \mathrm{~cm}$ of the core has lengths that are greater than 100 $\mathrm{cm}$ (i.e. the remaining $150 \mathrm{~cm}$ of core is completely intact), then $\mathrm{Cr}_{30}$ is 0.4 and $\mathrm{Cr}_{100}$ is 0.6 , and the final, $R C I$ value is 72 . The numerical constants in the $R C I$ equation are effectively weights, so that cores with longer intact sections will have higher $R C I$ values.

We tested the water sensitivity and dynamic disturbance response of some problematic geological bodies (e.g. fault gouges, weathered rocks, etc.) at the CSNS site; both characteristics can greatly affect the site stability, the construction quality control measures, and the engineering reinforcement implementation. Each of these analyses represents a single factor in the calculation of the Engineering Geological Suitability Index (EGSI):

$$
E G S I=\sum_{i=1}^{m} w_{i} f_{i}(x, y)
$$

Where $w_{i}$ is the weight ratio of influential factors, $f_{i}(x, y)$ is the normalized single factor influential function value, which ranges from 0 to 1 ,and each factor is evaluated at geographical coordinates $(x, y)$. In plane map models, an EGSI value can represent the individual EGSI values at a constant $(x$, $y$ ) and summed over varying depths.

We use the EGSI to comprehensively evaluate the geological conditions and determine how they might affect the site engineering. The EGSI quantifies the suitability of the conditions for construction and operation of the RI facility at a given site (Yang, 2018). Using the EGSI methodology is an improvement on the existing siting process, which relies heavily on subjective data and impressions. We can calculate the EGSI on large spatial scales (to identify RI locations) and small spatial scales (to identify where certain instruments should be located within the RI site) (Li, 2014). If the geotechnical parameters are sound, we can reasonably expect the long-term, stable, and efficient operation of the RI facilities. The purpose of normalization is to eliminate the unbalanced contributions of different factors to the ultimate result in order to make the data statistically comparable.

\subsection{The CSNS site}

The rocks exposed at the surface of the $400-\mathrm{mu}\left(266800 \mathrm{~m}^{2}\right.$ ) site, known as the SIA (Site Installation Area), are mainly composed of unconsolidated Quaternary sediments, Cretaceous granite, and Sinian gneiss. After dividing the 400-mu area (the SIA) of the CSNS site into 12086 sub-units, we calculated the EGSI value for each sub-unit. Using the standard mining method, we used the EGSI value and the size of each sub-unit to divide the SIA into engineering geological suitability zones per the natural breaks (Jenks) method in ArcGIS (Wu et al., 2004). An example of this approach for CSNS is shown in Fig.4. Guided by the EGSI index. 
(a) Suitability zonation

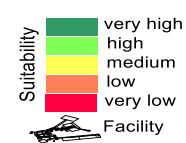

(b) Geohazards susceptibility

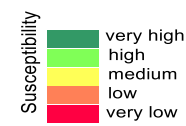

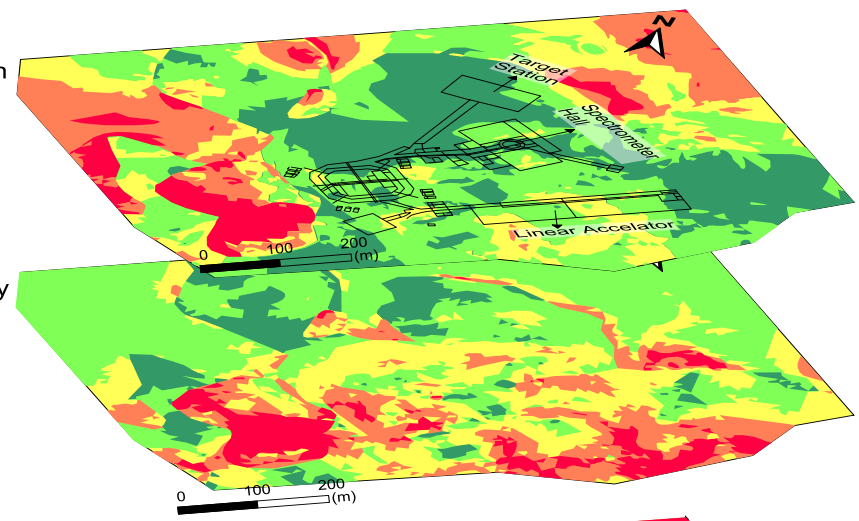

(c) Basement stability

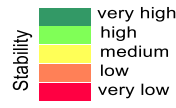

(d) Standard penetration

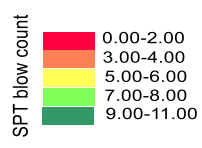

(e) Weathering thickness

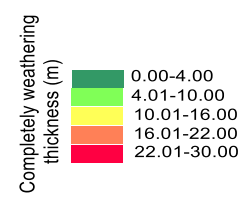

(f) Quaternary thickness

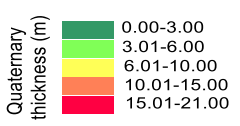

(g) Main lithology

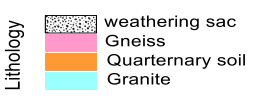

(h) Slope gradient

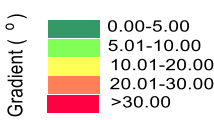
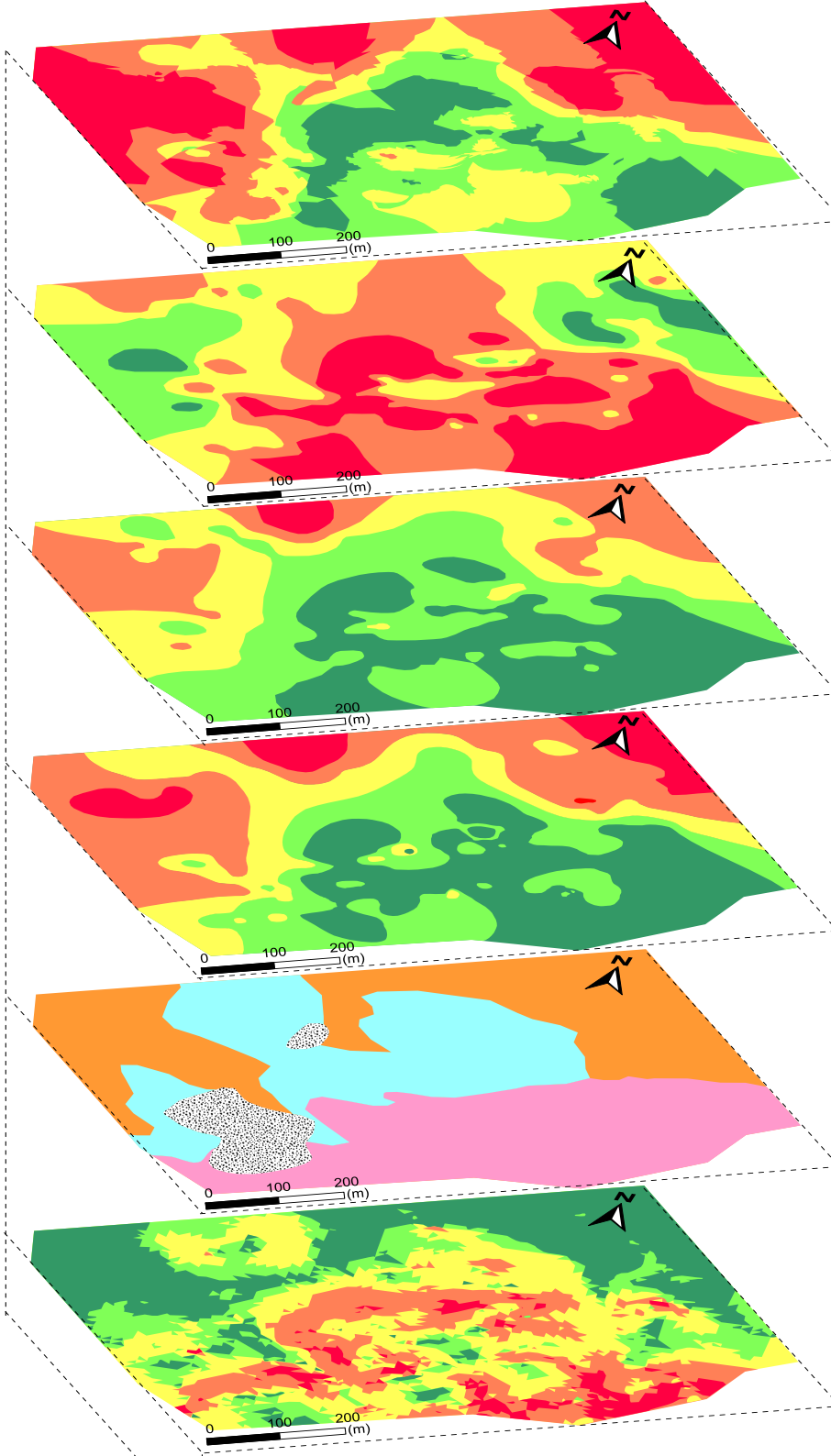

Figure4.Geological suitability index zonation for the CSNS site at different depths. 
We used ArcGIS software to quantify the factors that might affect the area's stability and suitability, such as potential geohazards, basement stability, weathering thicknesses, unconsolidated Quaternary sediment layer thicknesses, rock lithologies, and slope gradation (Fig. 4). This zoning map incorporates various influencing factors, including the foundation stability and the disaster susceptibility of the potential RI site; these factors provide actionable advice for designing and constructing the RI. As shown in Fig.4, the engineering geological suitability of the south central and southeastern parts of the SIA is better than it is for the northern part of this study area.

Based on this information, we see that the northern half of the SIA is more unstable than the southern half because of the presence of thick, highly weathered and/or unconsolidated Quaternary sediment layers that are highly fractured or have a low mechanical strength. The southern half of the SIA resides on exposed bedrock and is more stable from a geoengineering perspective. However, the combination of steeper slopes and the soft, fractured rocks located near the line accelator indicate that this part of the RI could be threatened by instability of the high cut slope (Fig.4b).

Taken together, the stability of the foundation and the disaster susceptibility of the installation area determine the engineering geological suitability. Based on this data, we recommended that the CSNS ring accelerator and the target zone device (middle position in Fig. 4a) should be placed in south central and southeastern parts of the site, rather than the northern part of the SIA. This recommendation was implemented during the construction of this part of the RI (IGGCAS, 2011).The CSNS borehole weathering shells are shown in Fig.5a.In the southern part of the site, the thickness of the weathered crust is small, extending to a depth of $\sim 10 \mathrm{~m}$. In the auxiliary area, which is located in alluvial soil, the Quaternary unconsolidated sediment layer and completely weathered granite layers are thicker and are visible throughout the entire borehole. The rock core index $(R C I)$ increases with depth (Fig. 5b) and generally corresponds to the different weathering zones. The $R C I$ of the underground cores throughout the entire CSNS site ranges from 0 to 30 , and the $R C I$ value of the borehole that samples fracture zone in the main device area is10.The $R C I$ of the Quaternary alluvial and completely weathered granites is about 0 , while the $R C I$ of the strongly weathered granite, slightly weathered granite, and fresh granite is $0 \sim 3,8$, and13, respectively. The $R C I$ values of the rock layer are generally less than 30 at depths less than $100 \mathrm{~m}$. 


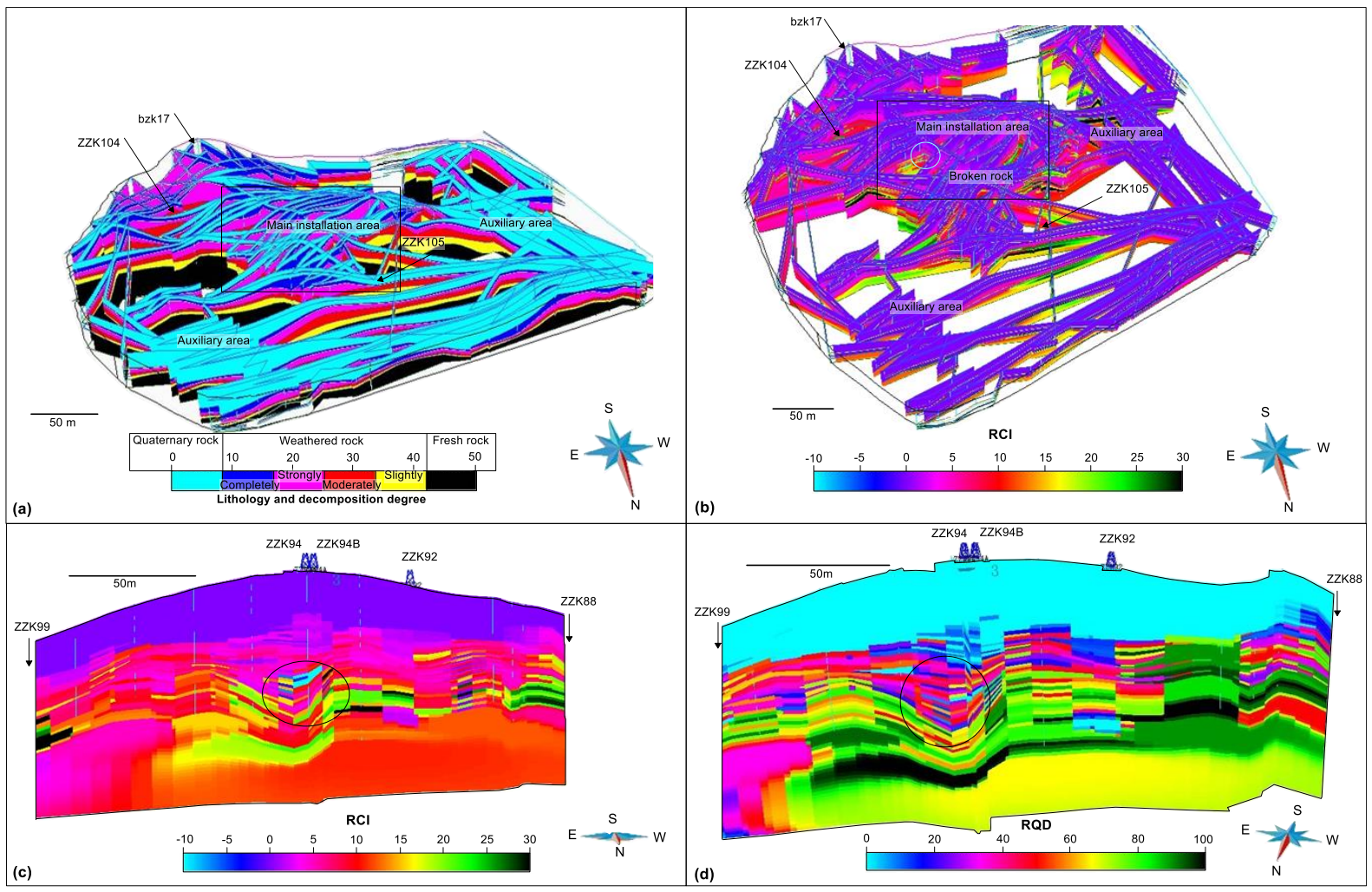

Figure 5.Geological modeling (using GOCAD software) of (a) weathering, (b)-(c) the $R C I$ values, and (d) the $R Q D$ values. Note: For the RCI,. The light blue layer represents a problematic geological body (e.g. fractured rocks or displaced soils).

When determining the stability and suitability of an RI site, we often investigate problematic geological bodies more thoroughly so that we can quantify both the horizontal and vertical extent of the body, as well as the potential effects this body will have on the engineering and architectural design of the RI. Our results were particularly instructive during the construction of CSNS; between the potentials for slope failure and the desire to avoid the intrusive contact zone between the gneiss and granite layers, the institute's orientation was shifted by $180^{\circ}$. The linear accelerator is located in the sloped area, and the target station, which requires a safe and stable foundation, is located at the top of a hill composed of slightly weathered granite from which $40 \mathrm{~m}$ of weathered cover was excavated.

Based on this analysis, the layout of the SIA at CSNS, including the layout of the main instruments, was altered. The final position of the ring accelerator was moved $\sim 150 \mathrm{~m}$ to the southwest. While the original target site was located on a steep slope, the adjusted target station was located at more stable granitic bedrock, a change that is conducive to the stable operation of the RIs equipment.

\section{5. discussion}


There are clear advantages to investigating the geotechnical parameters of an RI site prior to the design, construction, or operation process, as we have demonstrated with the DBNL and CSNS RI sites in this current study. By conducting rigorous geological and geophysical analyses, we submitted our recommendations to the engineers who design the RI sites and plan the RI construction process. We investigated six RI sites in different parts of China. Currently, most of the RI sites are being built according to our recommendations.

Our integrated geophysical exploration results indicate that several laboratories are located on sites with favorable geological conditions, but that the conditions of the tunnels connecting the labs fall along faults and weathering troughs and may experience a small amount of water seepage. Compared to the known existing conditions at this RI, our assessment is more than $85 \%$ accurate, demonstrating that our analyses can provide information relevant to laboratory design and tunnel construction safety. The successful implementation of our suggestions was commemorated with special ceremonies at DBNL in 2012 and CSNS in 2018.

\section{Conclusions}

It is vital to understand the impact that complex geological conditions will have on the planning and designing of RI sites, as demonstrated by so many RIs that are currently in various stages of completion in China.

Using jade carving technique composed of non-invasive, preliminary approaches, such as geological surveys, geophysical surveys, and targeted borehole drilling, we identified problematic geological bodies and quantitatively modeled the geotechnical parameters at two RI sites (DBNL and CSNS) that provided valuable insight into the optimal construction and geoengineering conditions during the RI site development. These techniques represent an affordable alternative to more extensive (and expensive) borehole studies.

Author Contributions: Shang YJ is primate investigator of all RIs and writes original draft. Yang CG was in charge of the DBNL. Jin WJ responds to the geophysical aspects of all RIs, and revised the original manuscript. Chen YW and Zhou M are in charge of the CSNS. Hasan revised the original manuscript. Y. Wang was in charge of the HIAF and ADS. Li K and D.M. Lin respond to the fig.4 and fig.5. All authors have read and agreed to the manuscript.

\section{Acknowledgements}

We would like to thank the workers who participated in the surveying and design of the RIs, as well 
as those who contributed to published papers and drafted reports on this topic. This research is financially supported by National Basic Research Program of China under Grant No. 2014CB046901 and the Chinese National Scientific Foundation Committee (NSFC) (No.41772320)

\section{References}

Azaiez H., Gabtni H., Bédir M. 2021, Joint Gravity and Seismic Reflection Methods to Characterize the Deep Aquifers in Arid Ain El Beidha Plain (Central Tunisia, North Africa). Water,13, 1310

Bukovskáa Zita,Soejono Igor, Vondrovi Lukáš, et al., 2019. Characterization and 3D visualization of underground research facility fordeep geological repository experiments: A case study of undergroundresearch facility Bukov, Czech Republic. Eng. Geol. 259,105-186.

Chang Kuan-Tsung, Abdelaziz Merghadi, Ali P. Yunus, et al., 2019. Evaluating scale effects of topographic variables in landslide susceptibility models using GIS based machine learning techniques. Scientific Reports. 9, 12296.

Chen Guoxing, Zhu Jiao, Qiang Mengyun, Gong Wenping, 2018. Three-dimensional site characterization with borehole data - A case study of Suzhou area. Eng. Geol. 234, 65-82.

Chen Y., 2011. China Spallation Neutron Source (CSNS). 26(6), 725-728.

Feng X.T., Wu S.Y., Li S.J., Qiu S.L., Xiao Y.X., Feng G.L., Shen M.B., Zeng X.H., 2016. Comprehensive field monitoring of deep tunnels at Jinping underground laboratory (CJPL-II) in China. Chinese Journal of Rock Mechanics and Engineering. 35(4), 649-657 (in Chinese with English abstract).

Florio M., Sirtori E., 2016. Social benefits and costs of large scale research infrastructures. Technological Forecasting \& Social Change, 112, 65-78.

Gao L., Ma C.M., Wang Q.X., et al., 2019. Sustainable use zoning of land resources considering ecological and geological problems in Pearl River Delta Economic Zone, China. Scientific Reports. 9, 16052.

Gu B.H., 2015. Commentary on typical cases of geotechnical engineering. Beijing: China Construction Industry Publishing House (in Chinese).

Hannes Krietsch, Joseph Doetsch, Nathan Dutler, et al., 2018. Data Descriptor: Comprehensive geological dataset describing a crystalline rock mass for hydraulic stimulation experiments. Scientific Data. 5,180269.

Hasan M., Shang Y., \&Jin W., 2018. Delineation of weathered/fracture zones for aquifer potential using an integrated geophysical approach: A case study from South China. Journal of Applied Geophysics. 157, 47-60.

Horvat M., 2011. The New Framework for EU Research and Innovation. Science.334 (6059), 1214295.

Huang Q.Y., 2014. Base zero subsidence control technology in multi boundary geological conditions. Guangdong Architecture Civil Engineering. (8), 37-40.

Institute of Geology and Geophysics, Chinese Academy of Sciences (IGGCAS), 2006. Engineering geological investigation report of Daya Bay neutrino experimental tunnel (feasibility study phase\& preliminary design phase). It includes 7 special reports. (1)Summary report of site mapping engineering technology; (2) Engineering geological mapping report; (3)Geophysical exploration report;(4)Engineering drilling report;(5)In situ stress test report;(6)Ultrasonic imaging test report;(7)Laboratory test report. 
Institute of Geology and Geophysics, Chinese Academy of Sciences (IGGCAS), 2007. General report on engineering geological investigation of Dongguan Dalang site of China spallation Neutron Source (feasibility study phase). It includes 2 special reports. (1)Engineering geological mapping report; (2) Geophysical exploration report.

Institute of Geology and Geophysics, Chinese Academy of Sciences (IGGCAS), 2011. Engineering geological investigation report of Beijing advanced light source (feasibility study phase).

Institute of Geology and Geophysics, Chinese Academy of Sciences (IGGCAS), 2013a. Engineering geological investigation report of LHAASO (feasibility study phase).

Institute of Geology and Geophysics, Chinese Academy of Sciences (IGGCAS), 2013b. Geophysical exploration report of LHAASO.

Institute of Geology and Geophysics, Chinese Academy of Sciences (IGGCAS),2014. Engineering geology and geophysical exploration report on the Daocheng site of LHAASO (feasibility study phase.

Institute of Geology and Geophysics, Chinese Academy of Sciences (IGGCAS),2015. General report of engineering geological investigation at Huizhou for ADS and HIAF (feasibility study phase ). It includes 2 special reports. (1)Geological survey report; (2) Geophysical exploration report.

Juang CharngHsein, Carranza-Torres Carlos, Crost Giovanni, et al., 2016. Engineering geology A fifty year perspective. Eng. Geol. 201, 67-70.

Juang CharngHsein, Gong Wenping, Martin II James R., Chen Qiushi, 2018. Model selection in geological and geotechnical engineering in the face of uncertainty-Does a complex model always outperform a simple model? Eng. Geol. 242, 184-196.

Kevin T., Lesko, William M. Roggenthen, William Chinowsky, et al., 2007. The Deep Underground Science and Engineering Laboratory at Homestake: Conceptual Design Report. http://wwwnsd.lbl.gov/homestake.

Li K., 2014. Site suitability assessment on large research infrastructures and its application. $\mathrm{Ph}$. D Thesis, Institute of Geology and Geophysics, Chinese Academy of Sciences.

Li, K., Shang, Y.J., He, W.T., Lin, D.M., Hasan, M., Wang K.Y., 2017. An engineering site suitability index (ESSI) for the evaluation of geological situations based on a multi-factor interaction matrix. Bulletin of Engineering Geology and Environment. 18(2), 1-9.

Lin D.M., 2012. Study on rock mass structure and geophysics features for granite in shallow-take CSNS for example. Ph. D thesis, Institute of Geology and Geophysics, Chinese Academy of Sciences.

Lisa P. Sousa, Ana I. Sousa, Fátima L. Alves, et al., 2016. Ecosystem services provided by a complex coastal region: challenges of classification and mapping. Scientific Reports. 6, 22782.

Major scientific and technological infrastructure of Chinese Academy of Sciences (MSTI), 2009. Suppl.4: The development of large scientific devices in the world [EB/OL]. http://www.lssf.cas.cn/zlyj/zlyjk/200912/t20091220_2711889.html.

Marcelli A., 2014. The large research infrastructures of the People's Republic of China: An investment for science and technology. Physica Status Solidi B. 251(6), 1158-1168.

National Development and Reform Commission of China (NDRC), 2017. National XIII Five-Year Plan for Major Scientific and Technological Infrastructure Construction. Feb 03, 2017 Economic Reference. http://finance.sina.com.cn/roll/2017-02-03/ doc-ifyaexzn8737139.shtml.

Pero H., 2011. Research infrastructures of pan-European interest: the EU and global issues. Nuclear 
Instruments and Methods in Physical Research A, 626-627.

Qiao L., Mu R., Chen K., 2016. Scientific effects of large research infrastructures in China. Technological Forecasting \& Social Change. 112, 102-112.

The State Council of China (SCC), 2013. Medium and Long Term Planning for Major National Science and Technology Infrastructure Construction (2012-2030).https:// baike.sogou.com/ v85308089.htm.

Scott Thacker, Daniel Adshead, Marianne Fay, et al., 2019. Infrastructure for sustainable development. Nature Sustainability, https://doi.org/10.1038/s41893-019-0256-8.

Shang Y.J., Shi Y.Y., Lin D., Wu FB., Zhang W., 2011. Analysis on relationship between buried depth and variation of in-situ stress in granitic rocks. Rock and Soil Mechanics. 32(5), 14301436.

Shang Y.J., Jin W.J., Chen Y.W., Li K., 2014. From the theory of rock mass structure controlling to site selection and evaluation practice for large scale scientific facilities. Journal of Engineering Geology. 22(4), 731-738.

Shang Y.J., Li K., Wang K.Y., et al., 2018a. Characteristics of karst development on the top of the plateau mountain: Taking the Shika Mountain as one example. Carsologica Sinica. 37(5), 639649.

Shang Y.J., Jin W.J., Wang K.Y., et al., 2018b. Characteristics of rock depth and resistivity in the alluvial-pluvial fan of Chaobai River: a case study of Mangniu River block in Yanqi development zone. Sciences Technology and Engineering. 18(17), 14-21.

Song J.B., Liu H., Wang W.J., Xiang X.O., 2007. The introduction and proceeding on sitting SKA and FAST radio telescope in Guizhou Province. Guizhou Science. 25(Suppl.), 86-97 (in Chinese with English abstract).

Stewart S., 2002. Exploring the continental shelf for low geological risk nuclear waste repository sites using petroleum industry databases: a UK case study. Eng. Geol. 67, 139-168.

Sun L., Liao X., Pan Z., 2015. Analysis of campus planning and architectural design of national scientific device: a case study of China Spallation Neutron Source. New Architecture. (3), 6871.

Sun S., Yin C., Gao X. 2021, 3D Gravity Inversion on Unstructured Grids. Appl. Sci. 11, 722.

Wang Y.F., Cao J., Chen S., et al., 2016. The 2013 annual report of physical analysis for Daya Bay Reactor Neutrino Experiment. Science and Technology Innovation Herald. (24), 184.

Wei S.Y., Jin W.J., et al., 2018. Discovery and explanation of muddy girdle under sharp turn of one ridge- a case study at the CSNS site of Guangdong Province. Journal of Engineering Geology. 26(3), 561-571. doi:10.13544/j.cnki.jeg.2017-045.

Wu L., Liu Y., Zhang J., et al., 2004. GIS-principle, approaches and application. Science Press.

Wu Shellen, 2019. How science saved China. Nature. 574, 25-28.

Xu J., Wang J., 2006. Assessment of rock mass quality based on rock quality designation and rock block index - Taking the Borehole BS01 in Beishan HLW disposal repository as example. Uranium Geology. 22(5), 295-299.

Yang P., 2018. Study on site selection and control for large research infrastructure under complicated geological conditions: a case study of CIADS and HIAF. Ph. D Thesis, Institute of Geology and Geophysics, Chinese Academy of Sciences.

Zhang C., 2004. The Beijing electron-positron collider and its second phase construction. Science \& Technology Review. (11), 23-27 (in Chinese with English abstract). 
